\title{
Influence of predation risk on the sheltering behaviour of the coral-dwelling damselfish, Pomacentrus moluccensis
}

\author{
Robin P. M. Gauff - Sonia Bejarano • Hawis H. Madduppa - Beginer Subhan • \\ Elyne M. A. Dugény • Yuda A. Perdana • Sebastian C. A. Ferse
}

Received: 27 August 2017 / Accepted: 11 January 2018 / Published online: 24 January 2018

(C) The Author(s) 2018. This article is an open access publication

\begin{abstract}
Predation is a key ecosystem function, especially in high diversity systems such as coral reefs. Not only is predation one of the strongest top-down controls of prey population density, but it also is a strong driver of prey behaviour and function through non-lethal effects. We ask whether predation risk influences sheltering behaviour of damselfish living in mutualism with branching corals. Host corals gain multiple advantages from the mutualistic relationship which are determined by the strength of damselfish sheltering. Distance travelled by the Lemon Damselfish Pomacentrus moluccensis away
\end{abstract}

Electronic supplementary material The online version of this article (https://doi.org/10.1007/s10641-018-0725-3) contains supplementary material, which is available to authorized users.

R. P. M. Gauff $(\bowtie) \cdot$ S. Bejarano • E. M. A. Dugény • S. C. A. Ferse

Department of Ecology, Leibniz Centre for Tropical Marine Research, Fahrenheitstraße 6, 28359 Bremen, Germany e-mail: gauff.robin@yahoo.de

R. P. M. Gauff • E. M. A. Dugény

Master of Science of the Universe, Environment, Ecology, Oceanography and Marine Environments Department, Université Pierre et Marie Curie, 4 Place Jussieu, 75252 cedex 05 Paris, France

H. H. Madduppa · B. Subhan · Y. A. Perdana Department of Marine Science and Technology (ITK), Faculty of Fisheries and Marine Sciences, Bogor Agricultural University (IPB), Jl. Agatis No. 1, Bogor 16680, Indonesia

S. C. A. Ferse

Faculty of Biology and Chemistry (FB2), University of Bremen, 28359 Bremen, Germany from their host colony was measured here as a proxy for sheltering strength and was expected to be shortest under highest predation risk. Predation risk, defined as a function of predator abundance and activity, turbidity and habitat complexity, was quantified at four reef slope sites in Kepulauan Seribu, Indonesia. Damselfish sheltering strength was measured using stationary unmanned video cameras. Small damselfish $(<2 \mathrm{~cm})$ increased their sheltering strength under high turbidity. Predator feeding activity, but not abundance, influenced damselfish sheltering strength. Contrary to our expectations, sheltering behaviour of adult damselfish decreased under high predator activity. While these observations are in line with riskaverse behaviour by juvenile $P$. moluccensis, they may indicate the presence of sentinel behaviour in the adults of this species. Habitat complexity seemed to be less important as a driver of damselfish behaviour. These counterintuitive results may indicate complex social behaviour and age-specific strategies for predator avoidance.

Keywords Top-down - Predation risk - Behaviour · Damselfish · Mutualism · Pomacentrus moluccensis

\section{Introduction}

Predation is a key process in terrestrial and marine ecosystems (Steele 1985). Not only does predation act as a top-down regulator of prey population densities, but it is also one of the strongest drivers of prey behaviour and trophic structure of biological communities (Lima and Dill 1990; Ritchie and Johnson 
2009; Estes et al. 2010; Boaden and Kingsford 2015). Predator abundance and predation intensity can vary in space and time (Bernstein et al. 1988; Bosiger et al. 2012). While the probability of being preyed upon may be a direct function of predator abundance and activity, predation risk can further be augmented by environmental factors which can influence either predators, prey, or both (De Robertis et al. 2003; Rilov et al. 2007; Wenger et al. 2013).

Predation plays a particularly important role in high-diversity ecosystems (e.g., coral reefs) by maintaining relative levels of species dominance and function (Hixon and Carr 1997). At the same time, species at higher trophic levels are disproportionally affected by human activities such as fishing, with potentially severe consequences for ecosystem functioning (Pauly et al. 1998; Estes et al. 2011). Overfishing of predators is a common ailment of many coral reefs around the world, yet the consequences of this on ecosystem functions remain poorly understood (Mumby et al. 2012; Fenner 2014; Maire et al. 2016). The release of the corallivorous crownof-thorns starfish (Acanthaster planci, Linnaeus, 1758) from predation pressure, for example, is believed to have contributed to pervasive outbreaks and large-scale coral mortality on Indo-Pacific reefs (Jackson et al. 2001; Baird et al. 2013). Sufficient levels of predation are essential for ecosystem functioning and the maintenance of ecological processes (Lima and Dill 1990; Catano et al. 2014). Carnivorous coral reef fishes (e.g., piscivores) comprise species-rich assemblages of both long-term inhabitants of the reef habitat and transient visitors (Boaden and Kingsford 2015). Changes or spatial differences in predator biomass and predation rates are likely to have consequences for prey abundance and behaviour (Mumby et al. 2012). Quantifying the spatial and temporal variability of predation rates is therefore fundamental to understand ecosystem functioning.

Intuitively, predation risk for coral reef fishes should vary proportionally with predator abundance and activity. However, this relationship is further influenced by environmental factors such as water turbidity and topographic complexity (hereafter referred to as rugosity) (Beukers and Jones 1997; Rilov et al. 2007; Leahy et al. 2011). These factors may have complex effects on the predator's ability to detect prey and/or the level of risk perceived by the prey. High turbidity results generally from the influx of terrigenous sediment into the ocean or resuspension and implies low light availability and poor contrast between objects and the environment (De Robertis et al. 2003). Turbidity may therefore affect the visual perception of both predators and prey (Utne-Palm 2002; De Robertis et al. 2003; Wenger et al. 2013). Whether either predators or prey are at greatest disadvantage in turbid reefs remains however incompletely understood. Predator success is assumed to be higher under turbid conditions, likely due to poor risk perception by prey fishes (Wenger et al. 2013). The alteration of the predator-prey interaction may however depend on prey size, colour and sensory abilities (Utne-Palm 2002). Piscivorous fish, for instance, might be at greater advantage in turbid reefs compared to prey, given that contrast decreases more sharply for big objects than for smaller ones, and thus the detection of larger fish (predators) may be more difficult (De Robertis et al. 2003).

Coral reef rugosity can also affect piscivorous predation rates. Both, positive and negative effects of rugosity are possible for prey and predators. Predators are assumed to be at a disadvantage in highly rugose habitats, where prey detection may be difficult and physical prey refugia are abundant (Beukers and Jones 1997; Figueiredo et al. 2015). In fact, prey have higher survival rates in sites with intermediate (Crowder and Cooper 1982) or high rugosity (Connell and Jones 1991), compared to flatter areas. However, this may not necessarily be the case for territorial and site-attached prey fishes whose location is predictable and constant. For species tightly associated with benthic structures, early visual detection of predators may be obstructed by physical obstacles. Ambushing or highly mobile piscivores may therefore benefit from highly rugose reefs where they may be less likely to be perceived by prey (Rilov et al. 2007). Accordingly, higher rugosity does not always correspond to high damselfish abundance (Bergman et al. 2000).

The level of predation risk may influence predator avoidance behaviour of prey fishes (Lima and Dill 1990), as well as behaviours implicated in their ecological functions (e.g., feeding rates). High predator abundance, for instance, can lead to diminished grazing rates of herbivorous fish (Catano et al. 2014). Such behavioural patterns resulting from predator avoidance can emerge in response to either acute or chronic predation risk (Madin et al. 2010). Certain planktivorous damselfishes display strong 
mutualistic relationships with branching corals, living in groups that use the coral branches for shelter to avoid predation and currents (Liberman et al. 1995; Holbrook et al. 2000). Corals benefit from this behaviour resulting in increased growth, survival and reproduction (Liberman et al. 1995; Holbrook et al. 2008). On reefs where heavy fishing pressure has reduced predator stocks, damselfishes might display a weaker sheltering behaviour than on predator-rich reefs. As reduced sheltering effectively decreases the benefits derived by host corals from mutualistic damselfishes, an indirect link between overfishing and coral health might exist (Garcia-Herrera et al. 2017). Predator avoidance behaviours of site-attached fishes may vary in response to the environmental conditions prevailing on a reef, independently of predator abundance, and may be size-dependent (Leahy et al. 2011; Helfman and Winkelman 2015). The size-spectrum theory predicts abundant small-bodied predators and few large-bodied ones (Sogard 1997). Small-bodied predators would only have access to small prey, whereas large-bodied predators would feed on a broad range of prey sizes (Juanes 1994; Juanes and Conover 1994; Scharf et al. 2000), resulting in a higher number of potential predators for smaller prey (Sogard 1997). The combined effect of multiple environmental and intrinsic mediators of predator-prey interactions is less clear, yet crucial for predicting ecosystem dynamics.

The present study investigates whether predation risk influences the sheltering behaviour of the damselfish Pomacentrus moluccensis (Bleeker, 1853). Predation risk was defined here as the probability of damselfish being preyed upon. The latter was assumed to be a function of predator abundance, level of predatory activity, and environmental moderators such as turbidity and rugosity. The distance at which damselfish hovered away from their host colony was used as a proxy for the strength of their sheltering behaviour. We hypothesised that under high predation risk, damselfish would remain within close range of their host coral colony, and under low predation risk they would venture further away from it. We also predicted that smaller damselfish would tend to stay closer to their host colony compared to larger ones because they are susceptible to being consumed by the full predators' size spectrum. We anticipate that clarifying how predation risk affects damselfish sheltering behaviour can help predict the spatial heterogeneity of this mutualistic association, and likely infer its stability.

\section{Materials and methods}

\section{Study area}

This study was conducted in the Kepulauan Seribu, a group of 110 islands located north of Jakarta off the coast of Java, Indonesia (Fig. 1). Most of these islands are flat, small-sized $(<10 \mathrm{ha})$, and relatively close to each other (Madduppa et al. 2013; Baum et al. 2015). Four patch reef sites were selected, aiming to include a range of low-to-high predator abundance. Two of them, namely Pulau Belanda and Pulau Pelangi, were $>2 \mathrm{~km}$ from the next densely populated island. Pulau Panjang and Pulau Kelapa were inhabited islets. All transects were deployed at the north-west side of the islets, except for Kelapa, where transects were deployed at the southwest side as conditions there were more suitable to the study design than the north side of the island.

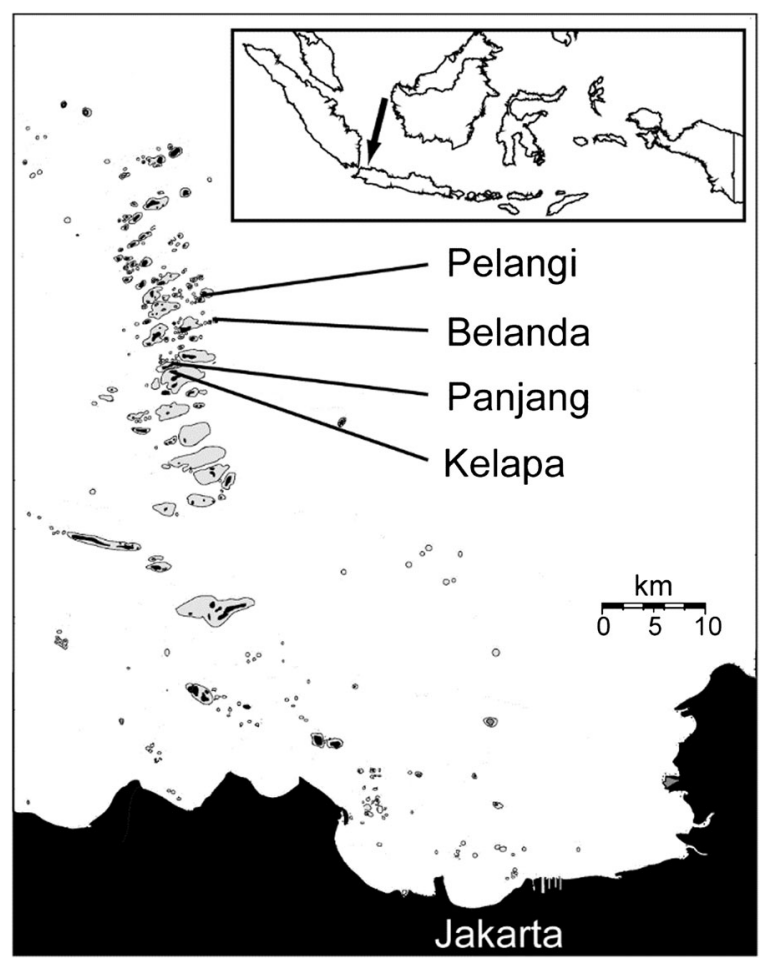

Fig. 1 Overview of the study region Kepulauan Seribu, northwest Java, Indonesia (location within Indonesia is indicated in the inset map). Study sites were located on the north-west coast of Pelangi, Belanda, Panjang and on the south-west coast for Kelapa 
Study species

Our study focused on the most abundant coral-dwelling damselfish in the study area, the Lemon Damselfish, Pomacentrus moluccensis. This medium-sized planktivorous species shows low specificity for the coral host (Pratchett et al. 2012), but is preferentially associated with live corals (Wilson et al. 2008; Hall and Kingsford 2016). Both P. moluccensis and the closely related Pomacentrus amboinensis (Bleeker, 1868) have been well-studied concerning larval dispersion and settlement (Öhman et al. 1998; Holbrook et al. 2000; Munkres et al. 2007; Pratchett et al. 2012), and also used as model species to understand predator recognition strategies indicating quick adaptation to predators (Mitchell et al. 2011, 2013; Bosiger et al. 2012; Bosiger and McCormick 2014) and social learning (Bosiger et al. 2012; Manassa et al. 2013, 2014; Hall and Kingsford 2016). The site-attached behaviour of P. moluccensis (Hall and Kingsford 2016) and its wellstudied behavioural response to predation make this an ideal model organism to assess the influence of predation risk on shelter-seeking behaviour.

Field surveys

\section{Quantifying predation risk}

Two proxies for direct predation risk for $P$. moluccensis were quantified in this study, namely predator abundance and predator activity. Both were assessed in each site at midday to coincide with the time of highest activity by $P$. moluccensis. Predator abundance was quantified using underwater visual censuses along belt transects. At each of the study sites, a total of six $50 \mathrm{~m}$ transects were deployed at a constant depth of $4 \mathrm{~m}$ parallel to the coastline. A distance of $25 \mathrm{~m}$ between consecutive transects was used to ensure independence. All transects were inspected by the same surveyor, who counted all fishes of five free swimming piscivorous families (Labridae, Lethrinidae, Lutjanidae, Nemipteridae, Serranidae, Table S1) within an area of two metres at either side of the transect. Cave- and sanddwelling predators were not counted due to the difficulty of precisely assessing their numbers on a belt transect. Second, levels of predatory activity were quantified using feeding assays at all sites. Dried squid meat cut into circular pieces of $13 \mathrm{~mm}$ in diameter was offered as bait, using a modification of a protocol previously used to quantify predation rates in tropical seagrasses (Duffy et al. 2015). Along the transects used to quantify predator abundance and after conducting all fish censuses, a total of 150 baited fiberglass sticks (25 per transect) were fixed to the substratum with squid bait attached to their upper end. Sticks on each transect were separated approximately $1 \mathrm{~m}$ from each other (Duffy et al. 2015), which resulted in six assays stretching over a distance of about $500 \mathrm{~m}$. Snorkelers counted the number of baits remaining 10,30 and $60 \mathrm{~min}$ after deployment, with the number of remaining bait assumed to be inversely related to predator activity. One to two GoPro Hero 3 cameras were placed in the vicinity of each transect to record the species responsible for the removal of bait on a subset of the assay.

\section{Quantifying the strength of sheltering behaviour in Pomacentrus moluccensis}

The distance swum by damselfish away from their host coral was considered here as an adequate proxy for the strength of their sheltering behaviour, and was quantified using video surveys. Because P. moluccensis shows low host specificity (Pratchett et al. 2012), ten branching coral colonies within $25 \mathrm{~m}$ of the transects were selected for video surveys irrespective of their species. Corals were considered only if they were completely alive and hosted at least two damselfish, but preference was given to colonies with more than two individuals. To facilitate the visualisation of the damselfish's position with respect to their host coral, we focused on isolated colonies that provided footage with a water column background. Filmed corals were at least $15 \mathrm{~m}$ apart from each other to minimise potential mutual influence and exchange of individuals. The cameras were aligned with the upper edge of the corals and fixed about $1.5 \mathrm{~m}$ away, recording the widest side of the colony if it was not equilateral. GoPro Hero3 cameras were set to record for at least $30 \mathrm{~min}$ in the absence of divers or snorkelers, immediately after a $30 \mathrm{~cm}$ size reference was held next to the coral. Upon camera retrieval, the host coral was measured and the number of damselfishes counted, classifying them into one of three size categories: small $(<$ $2 \mathrm{~cm})$, medium $(2-4 \mathrm{~cm})$, or large $(>4 \mathrm{~cm})$. The host coral species as well as adjacent colonies $(<5 \mathrm{~m}$ away) were photographed for posterior identification.

Posterior video analysis focused on twenty minutes of diver-free video and used 'VLC media player' (VideoLAN®, Version 2.2.1, Apr 2015). 
Distances swum by damselfish away from their host coral were assessed with a digital screen ruler (MBRuler) (Bader 2016). A single surveyor extracted the data from all videos. The first step consisted of confirming the number and sizes of damselfish present in the colony and scaling each video based on the $30 \mathrm{~cm}$ size reference shown initially. Data were then collected on still images captured every minute. On these images, the distances between the graphic centre of each damselfish and the nearest point of the coral, as well as the total length (TL) of each fish, were measured. Given that during video analysis, the $3 \mathrm{D}$ space in which damselfish move was projected onto a 2D plane (i.e. computer screen), measured distances may not have always reflected the exact distance between a fish and its host coral. This was particularly true for fish swimming towards the camera. These fish could have thus hovered at a greater distance from their coral than perceived by the observer. As a result, certain distances could have been underestimated during video analysis. Considering that this study focused on assessing relative rather than absolute distances, and that damselfish are randomly distributed around their host, the procedural bias was likely homogeneous across sites. Conclusions based on inter-site comparisons were therefore assumed to be minimally affected by this technical limitation. Furthermore, the position of the cameras filming the corals was chosen at random in relation to the spatial distribution of the fish. Even if damselfish groups did not distribute randomly in space, the relatively high sample size (20 snapshots per group and 10 groups per site) should have cancelled out this effect. Certain damselfish recorded in front of the coral were indistinguishable from others sheltering among the coral branches. For this reason, distances in both cases were measured as zeroes. Distances swum by fish that went outside the camera's field of view or behind the coral colony were not measured.

\section{Quantifying environmental moderators of predation risk}

Environmental factors likely to influence behaviour of predators and prey, and therefore mediate predation risk, were assessed at each site within a $5 \mathrm{~m}$ radius around the host coral colonies selected for video surveys. Rugosity was estimated visually on a scale from 0 (virtually flat) to 4 (highly rugose) based on the amount of vertical substrate, hideouts, and caves (Polunin and Roberts 1993). As a proxy of turbidity, horizontal visibility was quantified using a Secchi disk and a measuring tape deployed by two snorkelers at a depth of $1 \mathrm{~m}$.

Statistical analysis

\section{Spatial differences in predation risk}

Predation risk was considered a function of predator abundance, predator activity, rugosity and turbidity. To confirm that predation risk varied spatially, we analysed each of these variables separately for a site effect. In the case of turbidity and rugosity, which were non-normally distributed, comparisons were conducted using Kruskal-Wallis tests. Post-hoc pairwise comparisons with a Bonferroni correction were conducted to identify differences between particular sites whilst avoiding Type I errors arising from multiplicity (Bretz et al. 2011). The $p$-value for acceptance of results as significant was thus adjusted to 0.0083 . The total number of predators was calculated per transect, and differences among sites were tested using a generalised linear hypothesis test (glht) with the Tukey method for multiple comparisons (Bretz et al. 2011).

The feeding assays were assessed using survival analysis (Pyke and Thompson 1986) with the 'survival' $R$ package (Therneau 2015). The amount of remaining baits per transect at different times was recorded to calculate survival times per transect. Baits that were recorded missing 10 and 30 min into the feeding assay were assumed to have been consumed after the snorkeler's previous observation. Kaplan-Meier curves of bait survival were then computed per site (Kalbfleisch and Prentice 2002; Rich et al. 2010). The baits remaining at the end of the assay were regarded as having an unknown survival time, i.e. the assay data contained censored data (Pyke and Thompson 1986). We therefore used a Log-Rank multiple comparison with Bonferroni correction $(p$-value $=0.0083)$ to compare the survival rates in order to test whether sites differed in predation risk (Pyke and Thompson 1986; Rich et al. 2010). As a proxy of predator feeding activity, the time point at which $50 \%$ of the bait remained unconsumed was derived for each transect from an exponential curve, which was the best fit of the Kaplan-Meier curve. 
Influence of predation risk on damselfish sheltering behaviour

To determine the relative influence of predation risk and the environmental moderators of predation risk on the strength of damselfish sheltering behaviour (measured as the average distance swum by damselfish away from their host coral), a multiple regression was used. The complete model considered turbidity, rugosity, predator abundance and predator activity. We tested for collinearity among these factors by computing the variance inflation factor (VIF) of the complete model with the "car" package in $\mathrm{R}$ (Fox et al. 2017). A VIF value of 3 was chosen as a threshold for collinearity (Zuur et al. 2010). No factor exceeded the VIF threshold of 3, thus indicating there was no collinearity. Forward stepwise model selection was performed using the 'leaps' package in R (Lumley 2017), choosing parameters that decreased the AIC value of the model. A separate model was run for each damselfish size category to investigate whether prey size influences the relative roles of predation risk and the environmental factors that mediate predation risk as drivers of sheltering behaviour strength. We verified that these models conformed to normality and homoscedasticity by inspecting diagnostic residual plots (Zuur et al. 2010). The complete as well as the optimal model met the assumptions of normality and homogeneity of variances.

\section{Intrinsic drivers of damselfish sheltering behaviour}

The average strength in the sheltering behaviour of damselfish groups may be driven by the number of individuals within the group, due to damselfish performing optimal foraging, as well as by their mean total length, due to higher predation risk for smaller individuals (Townsend and Winfield 1985; Sogard 1997). To test this, we ran two separate linear models. Mean sheltering strength of all individuals per group was fitted as a function of the number of individuals within the group in a first model, and as a function of mean size category of the group in a second model. Lastly we verified that these models incurred no significant divergence from normality or heteroscedasticity (Zuur et al. 2010).

\section{Results}

Spatial differences of predation risk

Environmental factors considered here as moderators of predation risk (i.e. turbidity and rugosity) were significantly different among sites (Fig. 2a, b). Total predator abundance was significantly lower at Pelangi than at all other sites (glht Tukey, $p<0.025$ ). Predator feeding activity also differed among sites. Between 29.3 and $81.3 \%$ of bait was left $10 \mathrm{~min}$ after assay deployment, and $5.3-56 \%$ after $30 \mathrm{~min}$ of assay deployment. Unconsumed bait at the end of the experiment ranged from 0 to $34.7 \%$ (Fig. 2d). The highest predator feeding activity occurred at Belanda $(p<0.001)$, where visibility was also highest $(20 \mathrm{~m})$, and rugosity as well as predator abundance was moderate. Feeding activity was marginally higher at Kelapa compared to Pelangi (Log-rank, $p=0.054$ ). The consumption of 86 baits was documented by cameras. Camera recordings show that baits were mainly consumed by Pentapodus trivittatus (Bloch, 1791), Thalassoma lunare (Linnaeus, 1758) and Cephalopholis microprion (Bleeker, 1852) (24.4\%, $24.4 \%$ and $20 \%$ of baits, respectively).

Influence of predation risk on damselfish sheltering behaviour

Predator activity had a negative and significant effect on sheltering strength of entire damselfish groups $(p<0.001$, Fig. 3a, Table 1), whereas turbidity had a non-significant influence $(p=0.0883)$. Neither rugosity nor predator abundance were included as significant predictors in any of the final models. The sheltering behaviour of large damselfish $(>4 \mathrm{~cm}$ ) was weaker when predator activity was higher, as it was for medium-sized individuals $(2-4 \mathrm{~cm} ; p<0.001$ and $p=$ 0.0275 , respectively, Fig. 3b, Table 1). Sheltering behaviour was positively influenced by turbidity for smallbodied damselfishes $(<2 \mathrm{~cm} ; p=0.0227$; Table 1$)$ but unaffected by predator activity. The intercept of the model for this size category was not significantly different from zero, showing that under turbid conditions, small individuals hid among the coral branches.

Intrinsic drivers of damselfish sheltering behaviour

Sheltering behaviour of damselfish groups was strongly and negatively correlated with the mean size category of 

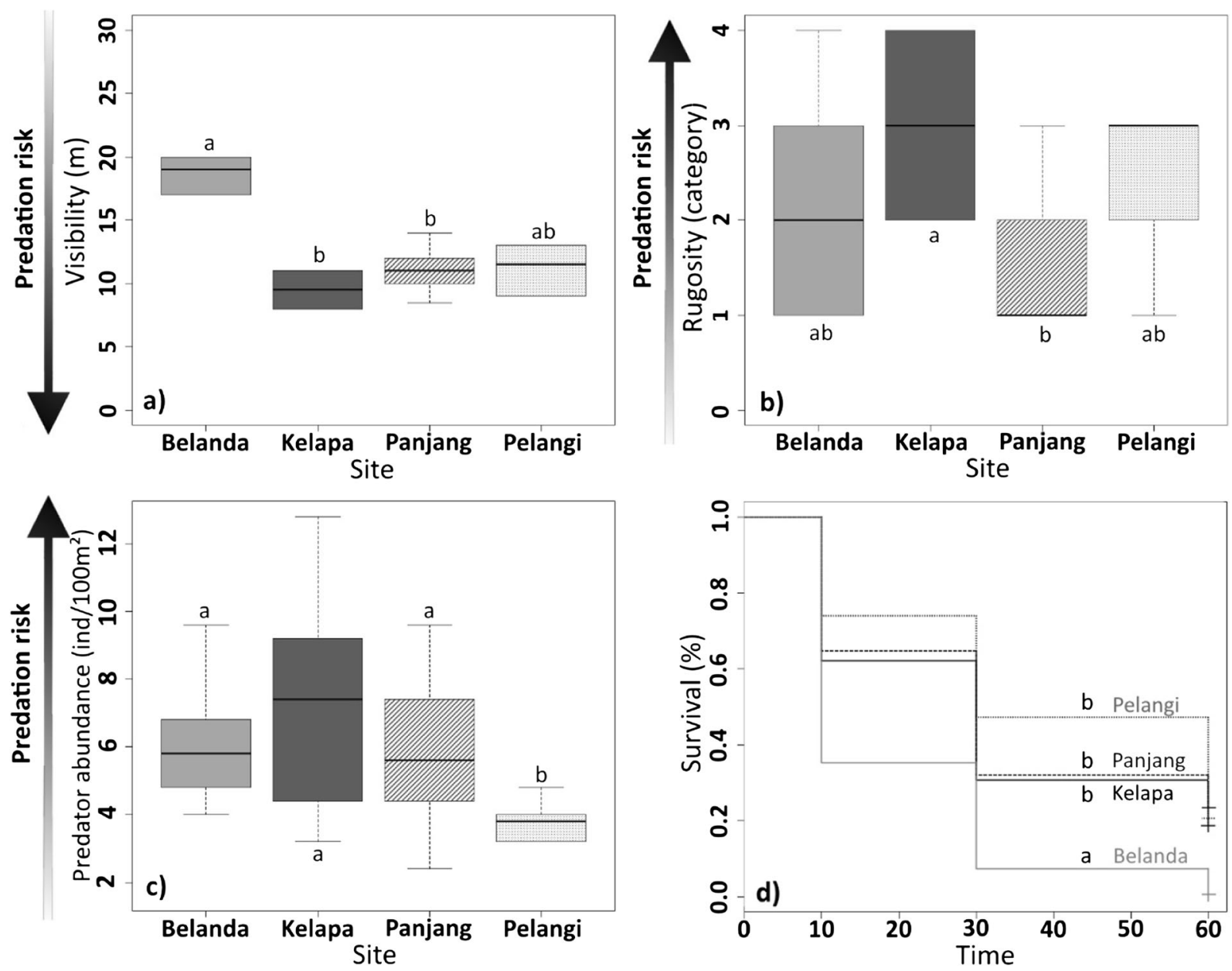

Fig. 2 Site differences of the four components of predation risk. a visibility (inversely proportional to turbidity); b rugosity; c predator abundance (total count of predators per transect); d

the group ( $p<0.001$, Fig. 4a). The largest damselfish ( $>$ $4 \mathrm{~cm}$ ) hovered about twice as far away from the host corals compared to medium sized $(2-4 \mathrm{~cm})$ and small $(<$ $2 \mathrm{~cm}$ ) individuals. The mean number of damselfish associated with a single host coral ranged between two and 17 but had no significant influence on sheltering behaviour of the group (Fig. 4b).

\section{Discussion}

The present study investigated whether predation risk influences the strength of the sheltering behaviour of damselfish living in mutualism with branching corals. We demonstrate that sheltering behaviour is indeed influenced by predation risk, which is consistent with
Kaplan-Meier survival curves of bait, with bait consumption used as proxy of predator activity. Lower-case letters indicate significant differences among sites

other studies indicating threat sensitivity and risk assessment by damselfish (Helfman 1989; McCormick and Manassa 2007; Leahy et al. 2011; Bosiger et al. 2012; Helfman and Winkelman 2015; Chivers et al. 2016). Predator activity rather than predator abundance was the main factor influencing damselfish sheltering behaviour. Similar observations were made for gobies, where a combination of visual and chemical (extract of an injured conspecific) alarm cues yielded the maximum anti-predator response (McCormick and Manassa 2007). The combination of these cues is associated to predator activity rather than mere abundance, given that an injury (or death) of a conspecific prey is required to provide the chemical cue required for the maximal response. However, the response to predation activity was the opposite of that identified in earlier studies. 


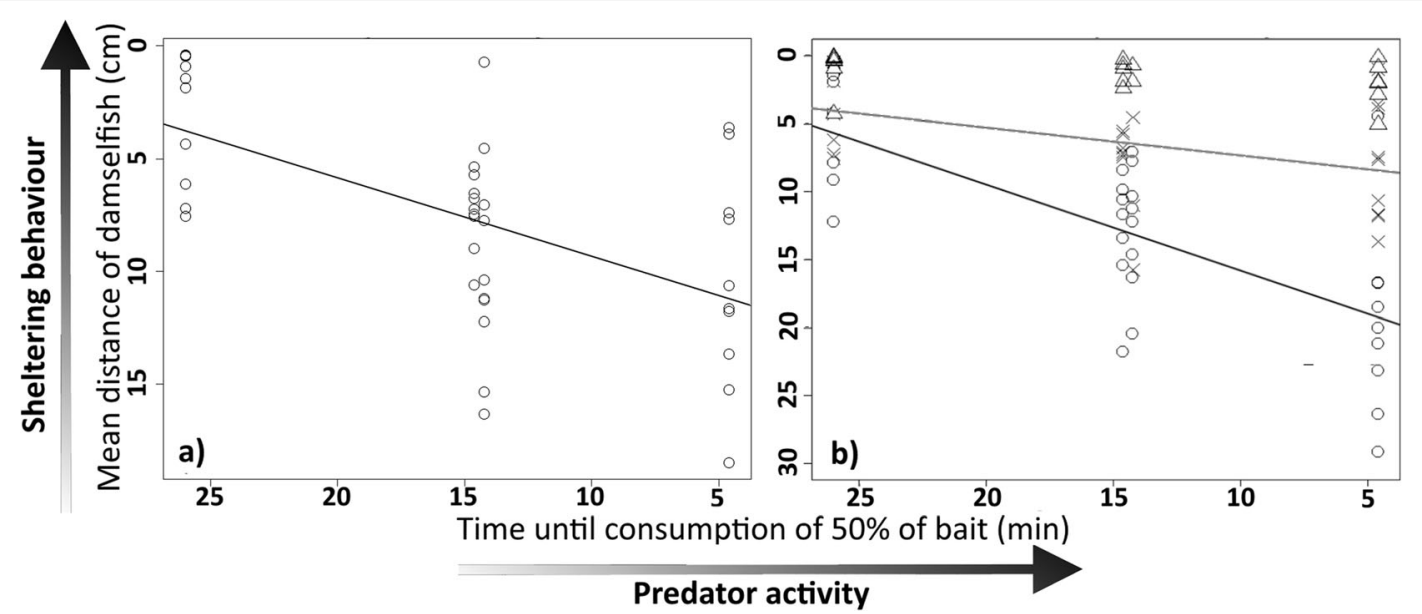

Fig. 3 Influence of predator activity on damselfish sheltering behaviour. a significant relationship between the sheltering behaviour of entire damselfish groups (i.e. including all sizes) and predator activity $\left(R^{2}=0.3172, p<0.001\right)$; b individual sheltering

Instead of increasing sheltering strength, predation activity seemed to decrease it. These results are counterintuitive since we expected sheltering behaviour would be strongest where predation activity, and therefore predation risk, were highest (Liberman et al. 1995). Turbidity influenced only the smallest damselfish, whereas rugosity was less important.

Our models demonstrate that damselfish sheltering behaviour is strongly influenced by the level of predator activity. Damselfish sheltering behaviour was weakest where predator activity was highest. This was particularly true for the largest damselfish. Sheltering behaviour varied regardless of predator activity for the smallest damselfish, but was significantly and positively influenced by turbidity. This could indicate that the smallest damselfish perceive high turbidity as an enhancer of predation risk, which is consistent with studies indicating a higher mortality and decreased foraging in high turbidity behaviour of each size category of damselfish (small: triangles, medium: crosses, large: circles) in relation to predator activity (small: $n s$; medium: $R^{2}=0.147, p=0.0275$; large: $R^{2}=0.447, \mathrm{p}$ $<0.001)$

conditions for other damselfish species (Leahy et al. 2011; Wenger et al. 2013).

Damselfish size had a strong effect on their sheltering behaviour. Groups of larger individuals displayed weaker sheltering behaviour than groups of smaller individuals. The size-spectrum theory predicts that smaller predators are more abundant than larger ones, which indicates that smaller prey may have a larger number of potential predators (Sogard 1997). Predator success as well as prey size selection depend on various parameters, such as mouth gape, that are largely influenced by predator size (Juanes and Conover 1994). Predators tend to target smaller prey items because this results in higher number of successful predation attempts (Juanes 1994; Juanes and Conover 1994). This further increases the potential number of predators of small-sized damselfish (Sogard 1997) and could explain the size-dependent sheltering behaviour observed here. Studies on the closely-related bicolor damselfish Stegastes partitus

Table 1 Components and environmental moderators of predation risk that had a significant effect on the sheltering strength of damselfish and were therefore retained in the optimal model

\begin{tabular}{lllllll}
\hline Size category & Predator activity & Predator abundance & Turbidity & Rugosity & AIC full & AIC optimal \\
\hline ALL SIZES & $(-)<0.0001$ & Disc. & $(+) 0.0883$ & Disc. & 109.8 & 106.6 \\
LARGE & $(-)<0.0001$ & Disc. & Disc. & Disc. & 108.3 & 89.5 \\
MEDIUM & $(-) 0.0275$ & Disc. & Disc. & Disc. & 76.7 & 74.6 \\
SMALL & Disc. & Disc. & $(+) 0.0227$ & Disc. & 13.9 & 10.5
\end{tabular}

The direction of the correlation as well as the $p$-value, or else discard (Disc.) in the optimal model, are shown for predator activity, predator abundance, turbidity and rugosity, for entire damselfish groups (i.e. including all sizes) and per size category. AIC values of the model containing all parameters and the optimal model are compared 

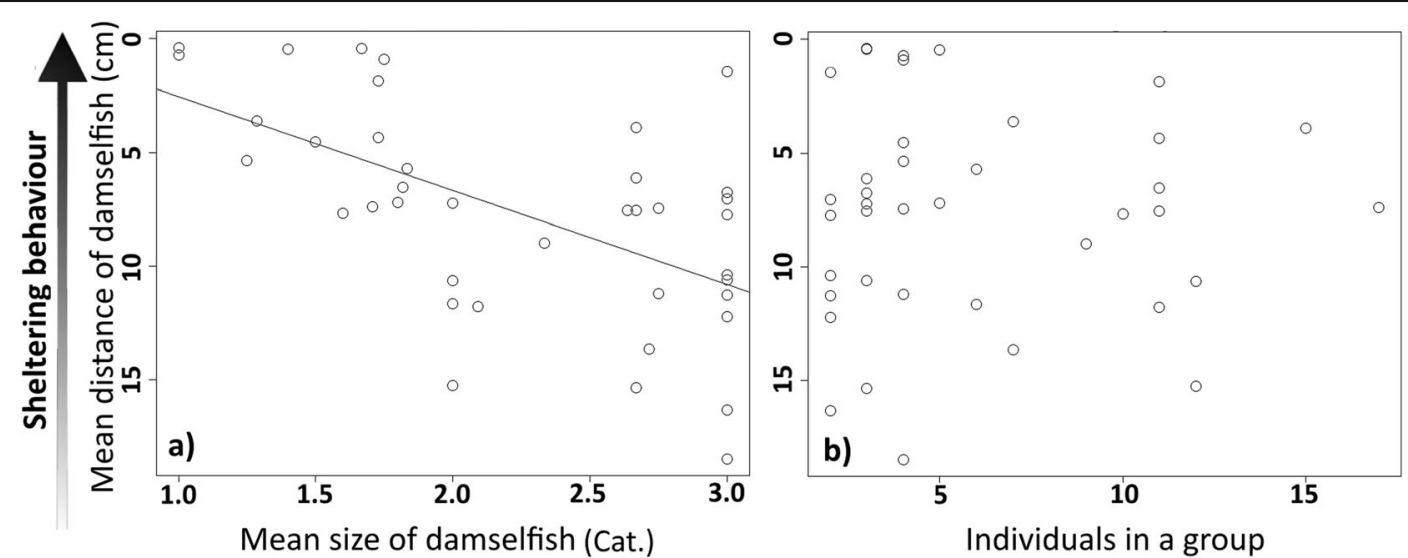

Fig. 4 Influence of mean size and number of individuals in damselfish groups on sheltering behaviour. a Significant relationship between sheltering behaviour and mean size of damselfish

$\left(R^{2}=0.3114, p<0.001\right)$; b no significant relationship between the number of individuals in a group and sheltering behaviour

(Poey, 1868) indicate that threat sensitivity depends on both the damselfish' and predator's body size (Helfman 1989; Helfman and Winkelman 2015). The species Stegastes planifrons (Cuvier, 1830), one of the most common damselfishes on Caribbean reefs, shows a similar, size-dependent response to predation risk. Smaller individuals display high sensitivity to threat, gradually reacting to danger, while larger individuals show a more indifferent behaviour, not always reacting to potential predators (Helfman and Winkelman 2015). According to the optimal foraging theory, larger groups of damselfish may prompt individuals to swim longer distances in the competitive pursue of plankton and optimal nutrition (Townsend and Winfield 1985). Group size seems, indeed, to act on the foraging of Dascyllus aruanus (Linnaeus, 1758) by diminishing the mean size of food items consumed and inducing an upstream swimming of highranked individuals (Forrester 1991). In the present study, the number of individuals within P. moluccensis groups did not influence shelter seeking. This might be due to the relatively small group sizes, as the mean number of individuals per group was 5.9 here compared to 7.9 in a similar study (Forrester 1991). This smaller group size might result in lower competition between individuals and thus a less pronounced optimal foraging effect. Other studies of damselfish show that no competition occurs between individuals within a group and that smaller individuals even increase energy uptake with higher density of conspecifics, which might also account for the observed results (Booth 2004).

Contrary to what we expected, damselfish in general exhibited weaker sheltering behaviour under high levels of predatory activity. We expand on a number of

possible explanations for this unexpected observation. Damselfish subject to high levels of predatory activity may tend to position themselves relatively high up in the water column, thus maximising their field of vision and predator detection. Coordinated vigilance has been observed for pairs of feeding rabbitfishes (Brandl and Bellwood 2015). P. moluccensis identifies usual predators rapidly and is capable of learning to recognise new predators and their activity patterns (Mitchell et al. 2011, 2013; Bosiger et al. 2012). An increasingly cautious behaviour under conditions of high predator activity would allow damselfish to quickly react to danger, and individuals exhibiting this behaviour may have a direct survival advantage. A sign of this potential learned predator response is that only large, likely more experienced individuals exhibited weak sheltering behaviour under high predation risk. Younger, thus smaller damselfish of the species Acanthochromis polyacanthus (Bleeker, 1855) have shown only a diffuse response to environmental moderators of predation risk (Leahy et al. 2011), likely because they have not yet developed predator awareness (Mitchell et al. 2011). Nonetheless, small individuals may still benefit from the behaviour of larger individuals in the group because they are capable of social learning and could react to the retreat of the adults even if they are naïve towards the predator itself, thus maximising their survival (Manassa et al. 2013). In the presence of adult conspecifics, juvenile damselfish have an increased growth rate due to higher food intake (Booth 2004). Since anti-predator behaviours (e.g. surveillance, sheltering) require a time and energy investment (Lind and Cresswell 2005), juvenile damselfish might profit from the behaviour of adult individuals by 
allocating less time to surveillance themselves and more time to feeding. Genetic relatedness among individuals within a group has been shown for several coraldwelling damselfish (Öhman et al. 1998; Buston et al. 2009). Individuals within a group do in fact maintain a strong hierarchical and social structure (Forrester 1991). This increases even further the potential fitness gain from vigilance behaviour by adults, since they would promote their own survival as well as survival of conspecifics, contributing to a stable altruism (Foster et al. 2006). By maintaining vigilance for the group, adult individuals increase their food intake and presumably their fitness, thus resulting in carryover maternal effects during gamete production, leading to increased fitness in offspring (McCormick and Gagliano 2008; Bonin et al. 2009). Therefore, it seems reasonable to suggest that our findings support the presence of sentinel behaviour in coral reef damselfishes. Sentinel behaviour is displayed when certain individuals of cooperative animal groups concentrate on scoping the environment for predators and warn conspecifics in case of an attack. Generally, sentinel behaviour increases with the perception of predation risk, and it is displayed by elder and more experienced individuals (Ridley et al. 2010). These conditions are met in the present case.

The observed pattern may also have been caused by a confounding factor simultaneously influencing both, predator activity and sheltering behaviour. Shallow incoming plankton clouds may, for instance, prompt damselfish to decrease sheltering behaviour in favour of foraging while simultaneously increasing levels of activity of predators attracted to exposed planktivores. Data on planktonic food items was not available to discard this possibility in the present study, and should be included in future studies of damselfish sheltering behaviour.

Alternatively, larger individuals may be more prone to display courtship and mating behaviour, prompting them to swim further from their host colony (Shpigel and Fishelson 1986). However, this would not explain the observed negative relationship to predator activity.

Both hypotheses underlying the observed behavioural patterns in larger individuals (i.e. foraging versus sentinel behaviour) could be easily verified by investigating the relationship among damselfish foraging activity, sheltering behaviour and levels of predator activity. If in response to increased food availability, foraging intensity of damselfish increases along with predator activity while damselfish sheltering behaviour weakens, a confounding factor (i.e. food availability) may be responsible for the observed reduction in sheltering. Alternatively, if sheltering behaviour of damselfish decreases with predator activity without an increase in feeding when food availability is high, then damselfish likely behave cautiously rather than engaging in foraging, and the weakened sheltering behaviour is linked to sentinel behaviour. Genetic studies of the relatedness between individuals within a group could back up the results in the second case.

In our study, predator activity was mainly accounted for by mesopredator species like $P$. trivittatus, $T$. lunare and C. microprion. Although these species might appear as low risk-inducing predators, mesopredators and particularly these species do consume coral-dwelling damselfish (Bonin et al. 2009; Holmes and McCormick 2010). An absence of apex predators in the feeding assay would therefore not explain the decreased sheltering behaviour observed here for large damselfishes where predator activity was high.

Here we considered the mean distance between damselfish and their host colony as an appropriate indicator of sheltering behaviour, but there are caveats to this assumption. Similar studies used the foraging rate (Hall and Kingsford 2016), the time spent inside and outside the coral (Rilov et al. 2007), or the maximum distance covered by the damselfish (Forrester 1991). Our proxy does however provide a reasonably precise metric of sheltering behaviour since it is influenced by both the maximum distance covered and the time spent inside and outside the coral. The quality of the footage obtained here was insufficient to quantify foraging rates. Future studies would however benefit from integrating mean distance of damselfish, food availability, and foraging rates, especially if there is an interest in detecting changes in the consistency of their ecological functions. Further precision could be achieved using stereoscopic cameras. A $2 \mathrm{D}$ projection of a $3 \mathrm{D}$ image results in a certain level of underestimation of the distance between damselfish and their host coral. However, the relative distance was sufficiently informative in our study.

Whilst sheltering, damselfish move their fins constantly, thus ventilating the small spaces between the coral branches, reducing hypoxia forming as a result of coral respiration at night (Goldshmid et al. 2004). They also increase available ammonium due to excretion (Holbrook et al. 2008) and defend their host from corallivores (Chase et al. 2014). Damselfish potentially contribute to the dissipation of excess oxygen produced by the photosynthesis of the corals. Some soft corals are known to produce small-scale currents by movements of 
their polyps to evacuate excess oxygen (Kremien et al. 2013). Damselfish are likely to produce similar effects on hard corals through the movement of their fins, and sheltering has been shown to contribute to increased photosynthesis (Garcia-Herrera et al. 2017). Ultimately, the mutualistic relationship with damselfishes results in increased growth, survival and reproduction of the host coral (Liberman et al. 1995; Holbrook et al. 2008). The magnitude of the benefits derived by host corals from sheltering damselfish may be determined by the consistency of their mutualistic association. Benefits may be decreased when damselfish spend less time sheltering. We originally hypothesised that low predation risk would result in weakened sheltering behaviour by P. moluccensis, thus leading to an alteration of the ecological link between damselfish and their host coral. Our results, however, show that the influence of predation risk on behaviour does not always conform to this expectation, underlining the complexity of predicting how changes in predation risk will influence the relationship between damselfish and their host coral. High levels of predation are generally taken as indicators of a healthy ecosystem (Parsons 1992; Jackson et al. 2001; Shurin et al. 2002; Boaden and Kingsford 2015). Although high levels of predator activity may decrease the strength of damselfish sheltering in their host coral and potentially decrease the benefits host corals can derive from mutualistic damselfish, this unexpected link between predation risk and sheltering behaviour does not appear widespread among coral-associated damselfish. A negative effect of high levels of predation on overall ecosystem health is therefore discarded. Certainly, behavioural responses of damselfishes to predation will vary among species or even populations of the same species. Further research is thus needed to accurately predict these dynamics.

Acknowledgements This study was authorised by the Indonesian Ministry of Research and Higher Education (RISTEKDIKTI, research permit number 262/FRP/E5/Dit.KI/II/2016) and the Taman Nasional Laut Kepulauan Seribu (Thousand Islands Marine National Park). Financial support by the Leibniz Society in the form of the SAW grant SAW-2014-ZMT-1 317 is gratefully acknowledged. Particular thanks to Claire, Francois and Marc Piton for providing accommodation during the stay in Indonesia.

Compliance with ethical standards All applicable international, national, and/or institutional guidelines for the care and use of animals were followed. This article does not contain any studies with human participants performed by any of the authors. No animals were collected or harmed during this study.
Open Access This article is distributed under the terms of the Creative Commons Attribution 4.0 International License (http:// creativecommons.org/licenses/by/4.0/), which permits unrestricted use, distribution, and reproduction in any medium, provided you give appropriate credit to the original author(s) and the source, provide a link to the Creative Commons license, and indicate if changes were made.

\section{References}

Bader M (2016) MB-ruler - the triangular screen ruler 5.3. http://www.markus-bader.de/MB-Ruler/download.php

Baird AH, Pratchett MS, Hoey AS et al (2013) Acanthaster Planci is a major cause of coral mortality in Indonesia. Coral Reefs 32:803-812. https://doi.org/10.1007/s00338-013-1025-1

Baum G, Januar HI, Ferse SCA, Kunzmann A (2015) Local and regional impacts of pollution on coral reefs along the thousand islands north of the megacity Jakarta, Indonesia. PLoS One 10:1-26. https://doi.org/10.1371/journal.pone.0138271

Bergman KC, Öhman MC, Svensson S (2000) Influence of habitat structure on Pomacentrus sulfureus, a western Indian Ocean reef fish. Environ Biol Fish 59:243-252. https://doi. org/10.1023/A:1007610023865

Bernstein C, Kacelnik A, Krebs JR (1988) Individual decisions and the distribution of predators in a patchy environment. $\mathrm{J}$ Anim Ecol 57:1007. https://doi.org/10.2307/5108

Beukers JS, Jones GP (1997) Habitat complexity modifies the impact of piscivores on a coral reef fish population. Oecologia 114:50-59. https://doi.org/10.1007 /s004420050419

Boaden AE, Kingsford MJ (2015) Predators drive community structure in coral reef fish assemblages. Ecosphere 6:1-33. https://doi.org/10.1890/ES14-00292.1

Bonin MC, Srinivasan M, Almany GR, Jones GP (2009) Interactive effects of interspecific competition and microhabitat on early post-settlement survival in a coral reef fish. Coral Reefs 28 : 265-274. https://doi.org/10.1007/s00338-008-0451-y

Booth DJ (2004) Synergistic effects of conspecifics and food on growth and energy allocation of a damselfish. Ecology 85 : 2881-2887. https://doi.org/10.1890/03-0535

Bosiger YJ, McCormick MI (2014) Temporal links in daily activity patterns between coral reef predators and their prey. PLoS One. https://doi.org/10.1371/journal.pone.0111723

Bosiger YJ, Lonnstedt OM, McCormick MI, Ferrari MCO (2012) Learning temporal patterns of risk in a predator-diverse environment. PLoS One. https://doi.org/10.1371/journal. pone. 0034535

Brandl SJ, Bellwood DR (2015) Coordinated vigilance provides evidence for direct reciprocity in coral reef fishes. Sci Rep. https://doi.org/10.1038/srep14556

Bretz P, Hothorn T, Westfall P (2011) Multiple comparisons using R. CRC Press, Boca Raton

Buston PM, Fauvelot C, Wong MYL, Planes S (2009) Genetic relatedness in groups of the humbug damselfish Dascyllus Aruanus : small, similar-sized individuals may be close kin. Mol Ecol:4707-4715. https://doi.org/10.1111/j.1365-294 X.2009.04383.X 
Catano LB, Shantz AA, Burkepile DE (2014) Predation risk, competition, and territorial damselfishes as drivers of herbivore foraging on Caribbean coral reefs. Mar Ecol Prog Ser 511:193-207. https://doi.org/10.3354/meps10921

Chase TJ, Pratchett MS, Walker SPW, Hoogenboon MO (2014) Small - scale environmental variation influences whether coral - dwelling fish promote or impede coral growth. Oecologia 176:1009-1022. https://doi.org/10.1007/s00442014-3065-9

Chivers DP, McCormick MI, Allan BJM, Ferrari MCO (2016) Risk assessment and predator learning in a changing world: understanding the impacts of coral reef degradation. Sci Rep: 1-7. https://doi.org/10.1038/srep32542

Connell SD, Jones GP (1991) The influence of habitat complexity on postrecruitment processes in a temperate reef fish population. J Exp Mar Biol Ecol 151:271-294. https://doi. org/10.1016/0022-0981(91)90129-K

Crowder LB, Cooper WE (1982) Habitat structural complexity and the interaction between bluegills and their prey. Ecology 63:1802-1813. https://doi.org/10.2307/1940122

De Robertis A, Ryer CH, Veloza A, Brodeur RD (2003) Differential effects of turbidity on prey consumption of piscivorous and planktivorous fish. Can J Fish Aquat Sci 60: 1517-1526. https://doi.org/10.1139/f03-123

Duffy JE, Ziegler SL, Campbell JE et al (2015) Squidpops: a simple tool to crowdsource a global map of marine predation intensity. PLoS One 10:e0142994. https://doi.org/10.1371 /journal.pone.0142994

Estes JA, Peterson CH, Steneck R (2010) Some effects of apex predators in higher-latitude coastal oceans. In: Throphic cascades: predators. Prey, And the Changing Dynamica of Nature, pp 37-53

Estes JA, Terborgh J, Brashares JS et al (2011) Trophic downgrading of planet earth. Science 80 . https://doi. org/10.1126/science. 1205106

Fenner D (2014) Fishing down the largest coral reef fish species. Mar Pollut Bull 84:9-16. https://doi.org/10.1016/j. marpolbul.2014.04.049

Figueiredo BRS, Mormul RP, Benedito E (2015) Structural complexity and turbidity do not interact to influence predation rate and prey selectivity by a small visually feeding fish. Mar Freshw Res:170-176. https://doi.org/10.1071/MF14030

Forrester GE (1991) Social rank, individual size and group composition as determinants of food consumption by humbug damselfish, Dascyllus Aruanus. Anim Behav 42:701-711. https://doi.org/10.1016/S0003-3472(05)80116-2

Foster KR, Wenseleers T, Ratnieks FLW (2006) Kin selection is the key to altruism. Trends Ecol Evol 21:55-57. https://doi. org/10.1016/j.tree.2005.11.014

Fox J, Weisberg S (2011) An R companion to applied regression, 2nd edn. Sage, Thousand Oaks

Garcia-Herrera N, Ferse SCA, Kunzmann A, Genin A (2017) Mutualistic damselfish induce higher photosynthetic rates in their host coral. J Exp Biol. https://doi.org/10.1242 /jeb. 152462

Goldshmid R, Holzman R, Weihs D, Genin A (2004) Aeration of corals by sleep-swimming fish. Limnol Oceanogr 49:18321839. https://doi.org/10.4319/lo.2004.49.5.1832

Hall A, Kingsford M (2016) Predators exacerbate competitive interactions and dominance hierarchies between two coral reef fishes. PLoS One 11:e0151778. https://doi.org/10.1371 /journal.pone.0151778

Helfman GS (1989) Threat-sensitive predator avoidance in damselfish-trumpetfish interactions. Behav Ecol Sociobiol 24:47-58. https://doi.org/10.1007/BF00300117

Helfman GS, Winkelman DL (2015) Threat sensitivity in bicolor damselfish : effects of sociality and body size. Ethology 103: 369-383. https://doi.org/10.1111/j.1439-0310.1997.tb00153.x

Hixon MA, Carr MH (1997) Synergistic predation, density dependence, and population regulation in marine fishes. Science 277(80):946-949. https://doi.org/10.1126 /science.277.5328.946

Holbrook SJ, Forrester GE, Schmitt RJ (2000) Spatial patterns in abundance of a damselfish reflect availability of suitable habitat. Oecologia:109-120. https://doi.org/10.1007 /PL00008826

Holbrook SJ, Brooks AJ, Schmitt RJ, Stewart HL (2008) E V ects of sheltering $\mathrm{W}$ sh on growth of their host corals. Mar Biol: 521-530. https://doi.org/10.1007/s00227-008-1051-7

Holmes TH, McCormick MI (2010) Size-selectivity of predatory reef fish on juvenile prey. Mar Ecol Prog Ser 399:273-283. https://doi.org/10.3354/meps08337

Jackson JBC, Kirby MX, Berger WH et al (2001) Historical overfishing and the recent collapse of coastal ecosystems. Science (80) 293:629-637. https://doi.org/10.1126 /science.1059199

Juanes F (1994) What determines prey size selectivity in piscivorous fish? In: Theory and application in fish feeding ecology. University of South Carolina Press, Columbia, pp 79-100

Juanes F, Conover D (1994) Piscivory and prey size selection in young- of-the-year bluefish: predator preference or sizedependent capture success? Mar Ecol Prog Ser 114:59-69. https://doi.org/10.3354/meps114059

Kalbfleisch JD, Prentice RL (2002) The statistical analysis of failure time data, 2nd edn. Wiley-Interscience, Hoboken. https://doi.org/10.1002/9781118032985

Kremien M, Shavit U, Mass T, Genin A (2013) Benefit of pulsation in soft corals. Proc Natl Acad Sci U S A 110:8978-8983. https://doi.org/10.1073/pnas.1301826110

Leahy SM, McCormick MI, Mitchell MD, Ferrari MCO (2011) To fear or to feed: the effects of turbidity on perception of risk by a marine fish. Biol Lett 7:811-813. https://doi.org/10.1098 /rsbl.2011.0645

Liberman T, Genin A, Loya Y (1995) Effects on growth and reproduction of the coral Stylophora Pistillata by the mutualistic damselfish Dascyllus Marginatus. Mar Biol:741-746. https://doi.org/10.1007/BF00349310

Lima SL, Dill LM (1990) Behavioral decisions made under the risk of predation: a review and prospectus. Can J Zool 68: 619-640. https://doi.org/10.1139/z90-092

Lind J, Cresswell W (2005) Determining the fitness consequences of antipredation behavior. Behav Ecol 16:945-956. https://doi.org/10.1093/beheco/ari075

Lumley T (2017) Package "leaps". https://CRAN.R-project. org/package=leaps

Madduppa H, Subhan B, Suparyani E et al (2013) Dynamics of fish diversity across an environmental gradient in the Seribu Islands reefs off Jakarta. Biodiversitas, J Biol Divers 14:1724. https://doi.org/10.13057/biodiv/d140103

Madin EMP, Gaines SD, Warner RR (2010) Field evidence for pervasive indirect effects of fishing on prey foraging behavior 
field. Ecology 91:3563-3571. https://doi.org/10.2307 129779540

Maire E, Cinner J, Velez L et al (2016) How accessible are coral reefs to people? A global assessment based on travel time. Ecol Lett 19:351-360. https://doi.org/10.1111/ele.12577

Manassa RP, McCormick MI, Chivers DP (2013) Socially acquired predator recognition in complex ecosystems. Behav Ecol Sociobiol:1033-1040. https://doi.org/10.1007/s00265013-1528-3

Manassa RP, McCormick MI, Dixson DL (2014) Social learning of predators by coral reef fish: does observer number influence acquisition of information? Behav Ecol Sociobiol 68: 1237-1244. https://doi.org/10.1007/s00265-014-1734-7

McCormick MI, Gagliano M (2008) Carry-over effects: the importance of a good start. Proc 11 th Int coral reef Symp 305310. https://doi.org/10.1016/j.anbehav.2015.01.033

McCormick R, Manassa MI (2007) Predation risk assessment by olfactory and visual cues in a coral reef W sh. Coral Reefs 27: 105-113. https://doi.org/10.1007/s00338-007-0296-9

Mitchell MD, McCormick MI, Ferrari MCO, Chivers DP (2011) Coral reef fish rapidly learn to identify multiple unknown predators upon recruitment to the reef. PLoS One. https://doi. org/10.1371/journal.pone.0015764

Mitchell MD, McCormick MI, Chivers DP, Ferrari MCO (2013) Generalization of learned predator recognition in coral reef ecosystems: how cautious are damsel fish? Funct Ecol:299304. https://doi.org/10.1111/1365-2435.12043

Mumby PJ, Steneck RS, Edwards AJ et al (2012) Fishing down a Caribbean food web relaxes trophic cascades. Mar Ecol Prog Ser 445:13-24. https://doi.org/10.3354/meps09450

Munkres KP, Bay LK, Jerry DR et al (2007) Development and characterization of microsatellite markers for parentage analyses of the coral reef damselfish (Pomacentrus Amboinensis: Pomacentridae). Conserv Genet 8:987-990. https://doi. org/10.1007/s10592-006-9208-8

Öhman MC, Munday PL, Jones GP, Caley MJ (1998) Settlement strategies and distribution patterns of coral-reef fishes. J Exp Mar Bio Ecol 225:219-238. https://doi.org/10.1016/S00220981(97)00224-4

Parsons TR (1992) The removal of marine predators by fisheries and the impact of trophic structure. Mar Pollut Bull 25:5153. https://doi.org/10.1016/0025-326X(92)90185-9

Pauly D, Christensen V, Dalsgaard J et al (1998) Fishing down marine food webs. Science 80. https://doi.org/10.1126 /science.279.5352.860

Polunin NVC, Roberts CM (1993) Greater biomass and value of target coral reef fishes in two small Caribbbean marine reserves. Mar Ecol Prog Ser 100:167-176. https://doi. org $/ 10.3354 /$ meps 100167

Pratchett MS, Coker DJ, Jones GP, Munday PL (2012) Specialization in habitat use by coral reef damselfishes and their susceptibility to habitat loss. Ecol Evol. https://doi. org/10.1002/ece3.321

Pyke DA, Thompson JN (1986) Statistical analysis of survival and removal rate experiments. Ecology 67:240-245. https://doi. org/10.2307/1938523
Rich JT, Neely JG, Paniello RC et al (2010) A Practival guide to understand Kaplan-Meier curves. Otolaryngol Head Neck Surg 143:331-336. https://doi.org/10.1016/j. otohns.2010.05.007.A

Ridley AR, Raihani NJ, Bell MBV (2010) Experimental evidence that sentinel behaviour is affected by risk. Biol Lett 6:445448. https://doi.org/10.1098/rsbl.2010.0023

Rilov G, Figueira WF, Lyman SJ, Crowder LB (2007) Complex habitats may not always benefit prey: linking visual field with reef fish behavior and distribution. Mar Ecol Prog Ser 329: 225-238. https://doi.org/10.3354/meps329225

Ritchie EG, Johnson CN (2009) Predator interactions, mesopredator release and biodiversity conservation. Ecol Lett 12:982-998. https://doi.org/10.1111/j.14610248.2009.01347.x

Scharf FS, Juanes F, Rountree RA (2000) Predator size - prey size relationships of marine fish predators: interspecific variation and effects of ontogeny and body size on trophic-niche breadth. Mar Ecol Prog Ser 208:229-248. https://doi. org $/ 10.3354 /$ meps 208229

Shpigel M, Fishelson L (1986) Behavior and physiology of coexistence in two species of Dascyllus (Pomacentridae, Teleostei). Environm Biol Fish 17(4):253-265. https://doi. org/10.1007/BF00001492

Shurin JB, Borer ET, Seabloom EW et al (2002) A crossecosystem comparison of the strength of trophic cascades. Ecol Lett 5:785-791. https://doi.org/10.1046/j.14610248.2002.00381.x

Sogard SM (1997) Size-selective mortality in the juvenile stage of teleost fishes: a review. Bull Mar Sci 60:1129-1157

Steele JH (1985) A comparison of terrestrial and marine ecological systems. Nature 313:355-358. https://doi. org $/ 10.1038 / 313355 \mathrm{a} 0$

Therneau T (2015) A package for survival analysis in S, version 2.38. https://CRAN.R-project.org/package=survival

Townsend CR, Winfield IJ (1985) The application of optimal foraging theory to feeding behaviour in fish. In: Tytler P, Calow P (eds) Fish Energetics, Springer Netherlands, Dordrecht, pp 67-98. https://doi.org/10.1007/978-94-0117918-8 3

Utne-Palm AC (2002) Visual feeding of fish in a turbid environment: physical and behavioural aspects. Mar Freshw Behav Physiol 35:111-128. https://doi.org/10.1080 $/ 10236240290025644$

Wenger AS, McCormick MI, McLeod IM, Jones GP (2013) Suspended sediment alters predator-prey interactions between two coral reef fishes. Coral Reefs 32:369-374. https://doi.org/10.1007/s00338-012-0991-z

Wilson SK, Burgess SC, Cheal AJ et al (2008) Habitat utilization by coral reef fish: implications for specialists vs. generalists in a changing environment. J Anim Ecol 77:220-228. https://doi.org/10.1111/j.1365-2656.2007.01341.x

Zuur AF, Ieno EN, Elphick CS (2010) A protocol for data exploration to avoid common statistical problems. Methods Ecol Evol 1:3-14. https://doi.org/10.1111/j.2041-210 X.2009.00001.x 